\title{
Team Teaching Technical Topics: An Innovative Approach to Instruction in an Introductory Civil Engineering Course
}

(ID 473)

\author{
Anna Phillips, Paul Palazolo, and Charles Camp \\ The University of Memphis
}

\section{Introduction}

This research presents findings from a pilot study involving a multi-disciplinary team-teaching instructional approach in an introductory civil engineering course. The study evolved from a radical redesign of the introductory course sequence in civil engineering in 1994, and the objectives of the pilot study focus an integrated approach to teaching communication skills, advanced critical thinking skills, and problem solving skills based on authentic civil engineering tasks.

During the spring semester of 1994, the Department of Civil Engineering at a large urban university in the Mid-South reviewed the courses offered for the freshman and sophomore years. The course offerings included a three-hour traditional surveying course, a three-hour course on computer usage, and a three-hour programming course. Each of the courses had been developed a number of years earlier and appeared to no longer reflect the skills or needs of student populations. Both faculty and student interest in these courses was waning. Students would often put these courses off until their final year in the program when they were "gotten over with". 
At the same time an internal departmental review was taking place, a series of meetings were being held with the department's external advisory board. In these meetings, the industrial and commercial representatives were emphasizing the need for stronger communication skills for new engineers entering the workplace. With the convergence of these two ideas, a complete redesign of the three-course sequence was undertaken. The disconnected three-course sequence was to be replaced by a sequential three-course sequence where each course would build on skills and knowledge developed in the previous course.

Each of the courses was targeted to emphasize critical thinking skills and problem solving skills with two major modes of instructional focus. The first would be skills that could be integrated into the student's course work beyond the entry level. These skills included surveying, other measurement skills, data collection and analysis, and computer skills including spreadsheets and programming. The second area of focus was on communication with a focus on writing and oral presentations.

In response to the goal of increased communication skills, traditional lecture-style instruction was extensively supplemented by a series of projects that the students completed in groups. Each project was designed to utilize all of the skill and learning components selected for emphasis in the sequence. As the students proceeded from the first class through the third class, they were exposed to similar projects with an ever-increasing level of sophistication and an increasing level of expected competency in the skills. 
Originally, two faculty members in the Department of Civil Engineering presented the courses as a team. Each of the faculty members was responsible for an equal share of the material to be presented and for an equal share of the evaluation. In the classroom, the complementary arrangement resulted in positive reviews from both the faculty members and from the students. The problem came in the evaluation and development of the students' writing and communication skills. While each of the faculty members felt competent in the evaluation of the technical part of the students' written and oral presentations, evaluation of the students' technical writing was more difficult. In actually evaluating the form and style, the evaluation became much more challenging, as there was more anecdotal than professional skills used for the evaluation. Students asked for more feedback than the teachers were able to provide. It was at this point that additional resources were committed to the class in the person of a professional writing instructor.

After consultation with the English Department, a writing instructor was selected to work as an integral part of the teaching team. The teacher selected was familiar with the scope of the engineering students' writing from having taught required technical writing courses within the English Department. With the civil engineering instructor working collaboratively with the writing instructor, writing assignments were developed in relation to the engineering course work being done by the students. With this new instructional format, all writing assignments were coupled closely with the engineering project work and presented along with the technical material in the classroom. 


\section{Pilot Design}

To address this problem and to develop possible solutions, the original course instructors designed and implemented a multi-disciplinary team teaching project. The team consists of two faculty members from the College of Engineering, Department of Civil Engineering, and one faculty member from the College of Arts and Sciences, Department of English. The new approach seeks to target civil engineering students in an introductory civil engineering course for an integrated approach to writing instruction and engineering instruction. Utilizing the team teaching approach, it is theorized that the project will link technical writing instruction to the previously stated goals of the civil engineering courses and extend these goals as evidenced by a measurable increase in the students' levels and awareness of technical writing proficiency and an increase the students' levels of analytical problem solving/critical thinking skills. The pedagogical design changes were selected after a careful consideration of previous educational research in the fields of technical writing and engineering instruction. A review of relevant literature reveals success in integrating technical writing instruction and engineering theory.

Evidence that these concepts can work is found in relevant research: similar programs with documented success were analyzed and modified to fit our particular situation, and the importance of utilizing previous research in this field cannot be overestimated. For example, Walker's research with integrating specific engineering genre rhetoric with technical writing instruction reports that initial success with the writing instruction would not have been possible without the participation and mentoring of the engineering faculty, chiefly in decoding and

explaining terms and nuances of engineering rhetoric. ${ }^{1}$ Furthermore, the preliminary studies by 
Sheehan and Flood encouraged us to design our class project assignments based on their "open case" approach which stresses the pedagogical importance of transferring school knowledge to workplace knowledge by identifying and practicing specific writing tasks as they would be performed in authentic situations. ${ }^{2}$

While improved writing skills were our initial focus in this research, the literature also documented possibilities of improved overall learning strategies and cognitive development. Piirto found that integrating argument strategy into the technical writing strategies used by engineering students produced students with higher levels of analytical depth and thought both in writing and in presenting technical information. ${ }^{3}$ Additional support of these ideas comes from Hedges and Walley who conducted research in their undergraduate civil engineering program by integrating communication skills with instruction in civil engineering design. They found greater amounts of learning that they attributed to learning one skill (the communication) and using it directly in application of executing another skill in civil engineering design. ${ }^{4}$ Most importantly for this research, Hedges and Walley also reported improved levels of writing in their students. ${ }^{4}$ Furthermore, Winsor's supposition that the engineer's writing represents the product first and foremost to the potential client provides motivational evidence that communication skills are an integral part of engineering education. ${ }^{5}$

Redd's applied research integrates expository strategies to find common links in goals between the writing required in introductory English classes and introductory engineering classes. ${ }^{6}$ In addition, Piirto also uses explicit strategies in instruction to teach writing in engineering classes with success. ${ }^{3}$ Bereiter and Scardamalia's research on teaching self-regulation in writing also 
applies here because the researchers provide concrete strategies and examples for use in teaching which can easily be customized for use in an engineering class. ${ }^{7}$

Writing research studies in composition theory by Flower, Kellogg, and Odell suggests multiple routes of problem solving through the writing process itself that includes metacognitive awareness, situational awareness, and rhetorical analysis. ${ }^{8,9,10}$ Their findings detail instruction that involves the student in active problem solving from multiple perspectives in both writing and engineering content.

The literature review also revealed an unexpected and interesting side effect of combining instructional techniques in the form of team teaching: increased student and faculty motivation. Hammons-Bryner and Robinson found a positive correlation between content choice and increased motivation in their writing students. ${ }^{11}$ This information is relevant to our work here because it aids in designing motivational instruction in the pilot class.

\section{Procedures}

Using the literature review as a guide, we designed and implemented a multi-faceted pilot system of instruction with the primary goal of enhancing critical thinking and problem solving skills through content-centered instruction supplemented with direct technical writing instruction. 


\section{Design Phase}

After reviewing the literature, the faculty members met several times to discuss ways of customizing writing instruction to the current civil engineering project requirements. Including representatives of the different departments was beneficial on several levels: first, these group discussions helped the civil engineering instructors to understand they were expecting writing skills at the freshman level that were not curricularly planned until the junior level when all engineering students take a course in technical communication. Second, it helped the writing instructor to see what real expectations exist for the engineering students in their disciplines. It was through discussions such as these that the teaching team came up with the idea to bring technical writing instruction to the introductory sequence of civil engineering courses on an "asneeded" basis.

The writing instructor reviewed the curricular goals of the first course in the introductory sequence, CIVL 1101, and planned technical writing instruction with the civil engineering instructors. On the first day of classes, both instructors were present and students were informed of the team approach to both instruction and evaluation. Throughout the remainder of the semester, both instructors were in the classroom during most of the classes, and there was joint instruction in writing and in technical information. Importantly, the writing instruction was customized to the technical topic being presented.

It was decided to devote the first ten minutes of most class periods to writing instruction, and the writing instruction was adapted to integrate the current topics and skills being addressed in the 
civil engineering course. For example, one of the first technical assignments includes a groupbased topographic map project where the students are required to design and complete a topographic study for a potential client. The writing instruction here began with an overview of the elements associated with a professional report, and each student submitted an individual sample letter of transmittal. Each of these letters was reviewed by the writing instructor and returned to the student with comments and suggestions for revision and/or incorporation into the final draft of the group project. With such detailed initial instruction and feedback regarding the professional focus of written communication in Civil Engineering, students are able to practice technical writing in conjunction with engineering projects.

\section{Implementation Measures}

In addition to instructional modifications, there were several other curricular and assessment revisions as a direct result of the multi-disciplinary approach. The major curricular change involved moving from a one-draft project submission to multi-step prewriting phase for each project where each student group turns in small parts of the larger project for instructor feedback before formal assessment of the final project. For example, each group submits a projectplanning sheet with self-selected group duties ranging from the group's lead writer, lead analyst, presentation manager, to the editor. The group editor works closely with the writing instructor on revision and modification of the individual parts of the assignment until the final project is due. The prewriting phase is beneficial to the students because it promotes group unity in the form of planning and drafting, and it allows for instructor feedback before assessment, thereby increasing the groups' confidence levels in meeting the expectations of the instructors. 
Assessment duties for the instructors have also been modified to allow each instructor to focus on their area of expertise. The civil engineering instructors evaluate projects for content, application, and implementation of engineering principles, and the writing instructor evaluates the formatting, organization, and quality of the technical writing. Both instructors use a criteriabased system of evaluation and students are provided easy access to and explanation of the evaluation criteria well in advance of each assignment. At the conclusion of each project, both instructors meet privately with each group to review the project evaluation, view a videotape of the group's formal oral presentation, and discuss the strengths and weaknesses of the group's performance against the project and skills criteria.

The students' response to this type of teaching is illustrative of how the complementary nature of the skills is perceived. In past classes without the diversity of expertise, both the students and the instructors often were not comfortable with the evaluation of the students' writing. With the additional expertise of the writing instructor, the students feel as if their writing is being evaluated by a professional and are more willing to utilize the feedback from the writing instructor to improve the quality of their writing.

\section{Pilot Data}

In order to assess the effectiveness of the multi-disciplinary instructional approach, two evaluations have been conducted with data generated during the fall 1999 classes. The first measure involves an externally reviewed letter of transmittal assignment in which each of the 
CIVL 1101 students was required to submit an individual letter of transmittal for the first group project. Because this assignment involving the letter of transmittal has not been modified since 1996, previous copies of letters for the same project were used as control comparisons.

\section{Letter of Transmittal Project}

To obtain preliminary data regarding changes in student writing, individual writing samples were collected from each student in the CIVL 1101 course in the form of a letter of transmittal. These letters were written as a prewriting part of a larger project in the course, and importantly, the letters were written after explicit instruction from the writing instructor accompanied by examples and opportunities for practice.

A total of 17 letters were collected from the fall 1999 CIVL 1101 class, and these letters were prepared for a blind review with a control group of letters consisting of 25 letters of transmittal from the 1996-1998 fall semesters of the CIVL 1101 course. All identifying information was deleted from the letters and copies were made and distributed to eight independent reviewers. Four reviewers were selected from the English Department, and the other four reviewers were Civil Engineering Department members who were not currently teaching the class. Reviews were returned by all four of the reviewers from the English Department and three of the four reviewers from the Civil Engineering Department. Each reviewer was asked to evaluate a randomly selected population of letters from all those collected and to assign a numeric score for each letter from 1-10 in the following categories: 
1. Format, including document design

2. Clarity of purpose

3. Statement of appreciation

4. Professional content and focus

5. Readability

Scores were evaluated and normalized to each reviewer to remove the departmental and reviewer bias toward the rating scale. The average normalized score was then generated for each of the five categories in both the before and after the introduction of the writing instructor in the teamteaching group. A comparison was made for the mean for the response to each question between the before and after groups. A statistical analysis was made for the difference between the means of the evaluations. The $3^{\text {rd }}$ category was removed from the analysis when it was discovered that the students in the before treatment group were never instructed that this should be a part of the letter while the after treatment group had this specifically pointed out to them.

With categories 1,2 , and 5, the means of the before and after treatment samples showed no significant sample difference from which was implied that there was no significant increase or decrease in the performance of the students in these categories. The $4^{\text {th }}$ category showed a strong statistical indication that the students in the after treatment group were more able to present a professional letter with a strong project focus. Reviewing course content for the before group showed that this had been emphasized before the introduction of the writing instructor, but that the professional expertise of the writing instructor and the opportunities for practice during class instruction time had sharpened the focus of the students into consideration of that aspect of the project. 


\section{Student Survey Measure}

The second evaluation project consisted of a quantitative and qualitatively based survey distributed to all students in the CIVL 1101 course. The survey was designed by the researchers to assess the students' responses and reactions to the multi-disciplinary instructional approach. It consisted of 13 Likert scale questions and 5 open-ended questions along with demographic information, and it was distributed to the students at the midpoint of the semester. All answers were anonymous and participation in the survey was voluntary.

The survey was designed to gauge the students' attitude toward the team-teaching and toward the inclusion of the multidisciplinary team makeup. A copy of the survey questions and the results is found in Table 1.

\section{Data analysis}

The results of the survey show that the students are very comfortable with the dual-expertise offered by two instructors from different disciplines, and find that adjusting to different teaching styles within a class is not a significant problem. Questions 1-4 were designed to examine the student's general attitude toward non-technical material being presented within a civil engineering designated class. The course content is directed toward developing the communication skills of the entering students and preparing them for future oral and written professional presentations. From the respondents' results, it appears that they are in close agreement that this focus of the class is important and that their skills in this area are being 
improved. Questions 5 and 6 were designed to see what impact the writing projects had on their development of working groups. While there is some indication that the writing improved the understanding of the group on the project itself, there is little evidence that group writing improved their cohesiveness in working as a group.

Questions 7, 8, and 11-13 were presented to gauge the students' responses to the interdisciplinary team teaching approach. The students appear very receptive to having the dual evaluation as evidenced by the $98 \%$ agreement from the seventh question. In the debriefing sessions with all of the groups, there was little of the aggressive defense of the writing that had been seen in the course before the incorporation of the writing instructor. In addition, $92 \%$ of the respondents saw a benefit to adding the expertise of the writing instructor. 


\section{Table 1: Results of Student Attitude Survey}

\begin{tabular}{|c|c|c|c|c|c|}
\hline & SA & A & $\mathrm{D}$ & SD & NO \\
\hline $\begin{array}{l}\text { 1. I feel that my writing skills have improved during } \\
\text { this class. }\end{array}$ & $2.9 \%$ & $67.6 \%$ & $8.8 \%$ & $2.9 \%$ & $17.6 \%$ \\
\hline $\begin{array}{l}\text { 2. I understand better what is required for a } \\
\text { professional report }\end{array}$ & $41.2 \%$ & $50.0 \%$ & $2.9 \%$ & $2.9 \%$ & $2.9 \%$ \\
\hline 3. I feel more comfortable making a presentation & $17.6 \%$ & $67.6 \%$ & $11.8 \%$ & $2.9 \%$ & $0.0 \%$ \\
\hline $\begin{array}{l}\text { 4. I have a better understanding of the importance of } \\
\text { communication to a civil engineer }\end{array}$ & $41.2 \%$ & $55.9 \%$ & $0.0 \%$ & $2.9 \%$ & $0.0 \%$ \\
\hline $\begin{array}{l}\text { 5. The writing of the report helped me/my group } \\
\text { understand and put into focus what I/we did during } \\
\text { the last project }\end{array}$ & $11.8 \%$ & $70.6 \%$ & $14.7 \%$ & $0.0 \%$ & $2.9 \%$ \\
\hline $\begin{array}{l}\text { 6. The development of the report focused my group } \\
\text { into working as a unit }\end{array}$ & $8.8 \%$ & $44.1 \%$ & $32.4 \%$ & $2.9 \%$ & $11.8 \%$ \\
\hline $\begin{array}{l}\text { 7. On your first project submission, a writing } \\
\text { instructor evaluated your technical writing skills } \\
\text { and a technical instructor evaluated the content of } \\
\text { the report. This allowed for a more complete } \\
\text { evaluation of your work }\end{array}$ & $44.1 \%$ & $52.9 \%$ & $0.0 \%$ & $0.0 \%$ & $2.9 \%$ \\
\hline $\begin{array}{l}\text { 8. There is a benefit to having a writing instructor and } \\
\text { a technical instructor working with your class }\end{array}$ & $58.8 \%$ & $35.3 \%$ & $2.9 \%$ & $0.0 \%$ & $2.9 \%$ \\
\hline $\begin{array}{l}\text { 9. I feel more comfortable with the writing } \\
\text { instructor's style of teaching }\end{array}$ & $23.5 \%$ & $52.9 \%$ & $0.0 \%$ & $0.0 \%$ & $23.5 \%$ \\
\hline $\begin{array}{l}\text { 10. I feel more comfortable with the technical } \\
\text { instructor's style of teaching }\end{array}$ & $8.8 \%$ & $38.2 \%$ & $23.5 \%$ & $0.0 \%$ & $29.4 \%$ \\
\hline $\begin{array}{l}\text { 11. A professional from a different discipline can } \\
\text { make a significant contribution to teaching this } \\
\text { class }\end{array}$ & $14.7 \%$ & $58.8 \%$ & $14.7 \%$ & $0.0 \%$ & $11.8 \%$ \\
\hline $\begin{array}{l}\text { 12. This is an easily observable difference between the } \\
\text { teaching styles of the writing instructor and the } \\
\text { technical instructor in this class }\end{array}$ & $14.7 \%$ & $67.6 \%$ & $11.8 \%$ & $0.0 \%$ & $5.9 \%$ \\
\hline $\begin{array}{l}\text { 13. I feel comfortable accepting the expertise for both } \\
\text { the writing instructor and the technical instructor in } \\
\text { this class }\end{array}$ & $29.4 \%$ & $58.8 \%$ & $8.8 \%$ & $0.0 \%$ & $2.9 \%$ \\
\hline
\end{tabular}

SA - Strongly Agree, A - Agree, D - Disagree, SD - Strongly Disagree, NO - No Opinion

The respondents were more reserved in their responses to the more general questions, 11-13, concerning the integration of instructors from outside the discipline. The close integration of the writing instructor and the engineering instructor appear to have allowed the students to accept the 
expertise of each instructor in this case. The students typically seem somewhat unwilling to accept a general condition of instructors from disciplines outside of engineering, especially those that seem to come from "softer" areas. With the close coordination however for these instructors, acting in tandem and closely correlated, the students responded very favorably, $88.2 \%$, to the combination of expertise.

\section{Discussion}

While the pilot evaluation projects are, of course, limited in scope by the time frame of instruction and the small size of the available sample, the data indicate that a multi-disciplinary approach to teaching writing as an integrated part of a civil engineering course is beneficial on several levels. First, the team-approach directly addresses the problem of instructor expertise and experience in the classroom: the engineering instructor is free to focus completely on engineering principles while the writing instructor focuses on the writing and communication parts of the instruction. Second, evaluation of student projects is shared, and therefore, easier for both instructors, and has the extra benefit of satisfying the students at the same time. Finally, our evidence suggests that students react well to the multi-disciplinary approach, and the finding that some students use the team interaction as models for problem solving adds credibility to the idea of extending knowledge in the classroom and preparing students for lifelong learning by equipping them with solid problem solving skills.

The key to the development and success of this type of team-teaching strategy is a close and seamless integration of topics, assignments, and duties between the team members. The students 
appear to value the material within the course in proportion to the weight the instructors give to the material. With a team that values both the technical and communication aspects of the course, the students are much more willing to expend the effort and time to develop their communication skills. The close integration of the technical with the non-technical appears to have eliminated some of the reluctance of the students to place adequate importance on the development of the non-technical skills.

The integration of multi-disciplinary instruction and content also appears to have increased the students' awareness of problem solving strategies through modeling. As our surveys indicated, the different teaching styles of the instructors appealed to the students overall, and as an added instructional bonus, the instructors were also able to model successful strategies for critical thinking and active problem solving on a daily basis through consistent and planned instructional methods. This instructional strategy is supported by the cognitive constructivist theory that all new knowledge must be delivered in relation to previous knowledge in order for maximum learning to take place.

\section{Suggestions/Implications for Future Research:}

As an additional bonus, our pilot research supports and complements much of the ABET 2000 criteria for accrediting engineering programs. For example, in the General Criteria guidelines, our program supports Section 1B: Intent of criteria as this program "encourages and stimulates creative and imaginative programs". ${ }^{12}$ We also meet the Guidelines for Faculty in all applicable sections, because by including a writing instructor with diverse professional and educational 
training with more traditionally trained engineering instructors, we are able to demonstrate ABET's goals of "stability, continuity, and high morale" which further motivate and encourage our students to complete their undergraduate studies and begin their professional engineering careers with a high degree of optimism and preparation.

Most importantly, our multidisciplinary approach to engineering education allows us to fulfill and extend ABET's guidelines to develop and implement a program which trains students in the diversity of engineering issues which extend on engineering principles and prepare the student for a lifetime of learning and working as an engineer. Because the students are able to personally interact with instructors in our program who model and discuss multi-faceting engineering concerns on a daily basis from multiple perspectives, the students are able to view and participate in the types of engineering experiences they will encounter as professional engineers.

\section{Conclusions}

Based on these findings, we plan to continue the project in our department, and we hope to extend the educational research base by designing and implementing a longitudinal study beginning with the freshmen students from the 1999 class. We plan to track these students as they advance through the civil engineering undergraduate program, and we hope to be able to note a long-term improvement in technical writing proficiency and problem solving skills. And again, we urge other engineering educators to consider a multi-disciplinary approach that combines technical writing with technical instruction in order to extend the research base and add to our knowledge about successful classroom instructional strategies in engineering classrooms. 


\section{Bibliography}

1. Walker, K. Genre Theory in Teaching Engineering Lab Report Writing. In IEEE Transactions on Professional Communication, Vol. 42, No. 1, 9-19, March 1999.

2. Sheehan, R. \& Flood, A. Genre, Rhetorical Interpretation, and the Open Case: Teaching the Analytical Report. In IEEE Transactions on Professional Communication, Vol. 42, No.1, 2031, March 1999.

3. Piirto, J. Teaching Writing to Engineering Students: Toward a Nontechnical Approach. In Journal of Technical Writing and Communication, Vol 26 (3), 307-313, 1998.

4. Hedges, P. and Walley, W.J. An Approach to the Integration of Communication Skills Development within an Undergraduate Civil Engineering Program. Journal of Technical Writing and Communication, Vol. 20, 165-175, 1990.

5. Winsor, D. Joining the Engineering Community: How do Novices Learn to Write Like Engineers? Technical Communication, Vol. 37, 171-179 (1990).

6. Redd, T. Exposition by Design: Using Expository Strategies to Link Freshman English and Introduction to Engineering. in Composition Studies/Freshman English News, Vol, 25, 6782, 1996.

7. Bereiter, C. and Scardamilia, M. Fostering Self-Regulation. The Psychology of Written Composition. Hillsdale, NJ: Erlbaum Publishers, 249-263, 1987.

8. Flower, L. Metacognition: A Strategic Response to Thinking. In The Construction of Negotiated Meaning. Southern Illinois University, 223-262, 1984.

9. Kellogg, R.T. Strategies. In The Psychology of Writing. New York: Oxford University Press, 249-263, 1994.

10. Odell, L. Teaching Writing by Teaching the Process of Discovery: an Interdisciplinary Enterprise. In L. Gregg and E. Steinberg (Eds.) Cognitive Processes in Writing, Hillsdale, NJ: LEA, 139-159, 1980.

11. Hammons-Bryner, S. and Robinson, B. Excitement in Core Curriculum Classes. College Teaching, Vol. 42, 97-100, 1994.

12. Engineering Criteria 2000, $3^{\text {rd }}$ Edition, Engineering Accreditation Commission, Accreditation Board for Engineering and Technology, Inc., Baltimore, MD, Pub. No. 98AB-7a, 1998. 


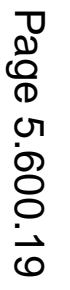

